Thorax (1975), 30, 521.

\title{
Surgical stabilization of traumatic flail chest
}

\author{
F. PARÍ́ ${ }^{1}$, V. TARAZONA ${ }^{1}, E$. BLASCO$^{1}, A$. CANTO, \\ M. CASILLAS ${ }^{1}$, J. PASTOR ${ }^{1}$, M. PARÍS ${ }^{2}$, and \\ R. MONTERO ${ }^{2}$
}

Thoracic Surgery Service, Department of Surgery ${ }^{1}$ and Department of Anaesthesia-Reanimation, Centro Hospitalario 'La Fé', Valencia 9, Spain

\begin{abstract}
París, F., Tarazona, V., Blasco, E., Cantó, A., Casillas, M., Pastor, J.; París; M.; and Montero, R. (1975). Thorax, 30, 521-527. Surgical stabilization of traumatic flail chest. Since 1970 we have stabilized the ribs to correct paradoxical movement of the chest wall in chest injuries, using an original technique, in order to avoid as far as possible the need for long-term chest wall stabilization by intermittent positive pressure respiration (IPPR).

The technical details of surgical stabilization are described, and the different types of stainless steel struts are shown. Type I was originally used either as an intramedullary nail or as an external brace. Types II and III were designed for external fixation of the strut to the rib.

Treatment of 29 patients with severe flail chest, classified into four groups, is shown: group I was treated by IPPR, group II by IPPR plus surgical stabilization, group III by surgical stabilization only, and group IV by surgical stabilization after exploratory thoracotomy.

The clinical results are discussed. We conclude that surgical stabilization of the paradoxial movement of the chest wall can avoid the use of the respirator or at least reduce the interval of IPPR to a short period during the initial recovery from trauma. Using type III struts, we have obtained stabilization of the flail chest in all cases even in patients with severe anterior paradoxical movement. The patients' tolerance of surgical stainless steel struts was good.
\end{abstract}

Although single uncomplicated fractures of the ribs are usually not serious, the prognosis is not the same when rib fractures are multiple or bilateral, or a fractured sternum coexists. In these circumstances part of the chest wall may move paradoxically.

The treatment of severe chest wall injury with paradoxical respiration remains a matter of controversy. Twenty years ago, fixation of ribs was considered useless because encircling sutures or screws or the insertion of thin nails did not abolish paradoxical movement. For this reason Avery, Mörch, and Benson (1956) considered stabilization of the chest wall by intermittent positive pressure respiration (IPPR) the most appropriate treatment.

Recently, however, Dor et al. (1972), Couraud, Bruneteau, and Durandeau (1973), Eschapase and Gaillard (1973) and others have reintroduced various procedures for rib fixation. Joudet (1973) used struts composed of a bar with two staples at both ends for embracing the rib on both sides of the fracture. Similar struts have been described by Sanchez Lloret (1974). Since 1970 we have fixed the ribs to correct paradoxical movement of the chest wall in chest injuries using an original technique. The early results have already been reported (París, 1972).

Rib fixation has been re-evaluated in order to avoid as far as possible the need for long-term chest wall stabilization by IPPR. The disadvantages and dangers of IPPR are: the method is uncomfortable and requires meticulous care; difficulty in communication and the long period of bed rest are irksome to the patient; it can increase air leaks from the lung; it does not always correct traumatic thoracoplasty or avoid the healing of flail chest in a bad position, producing a stove-in deformity; it adds the complications of tracheostomy such as infection, tracheal stenosis, 


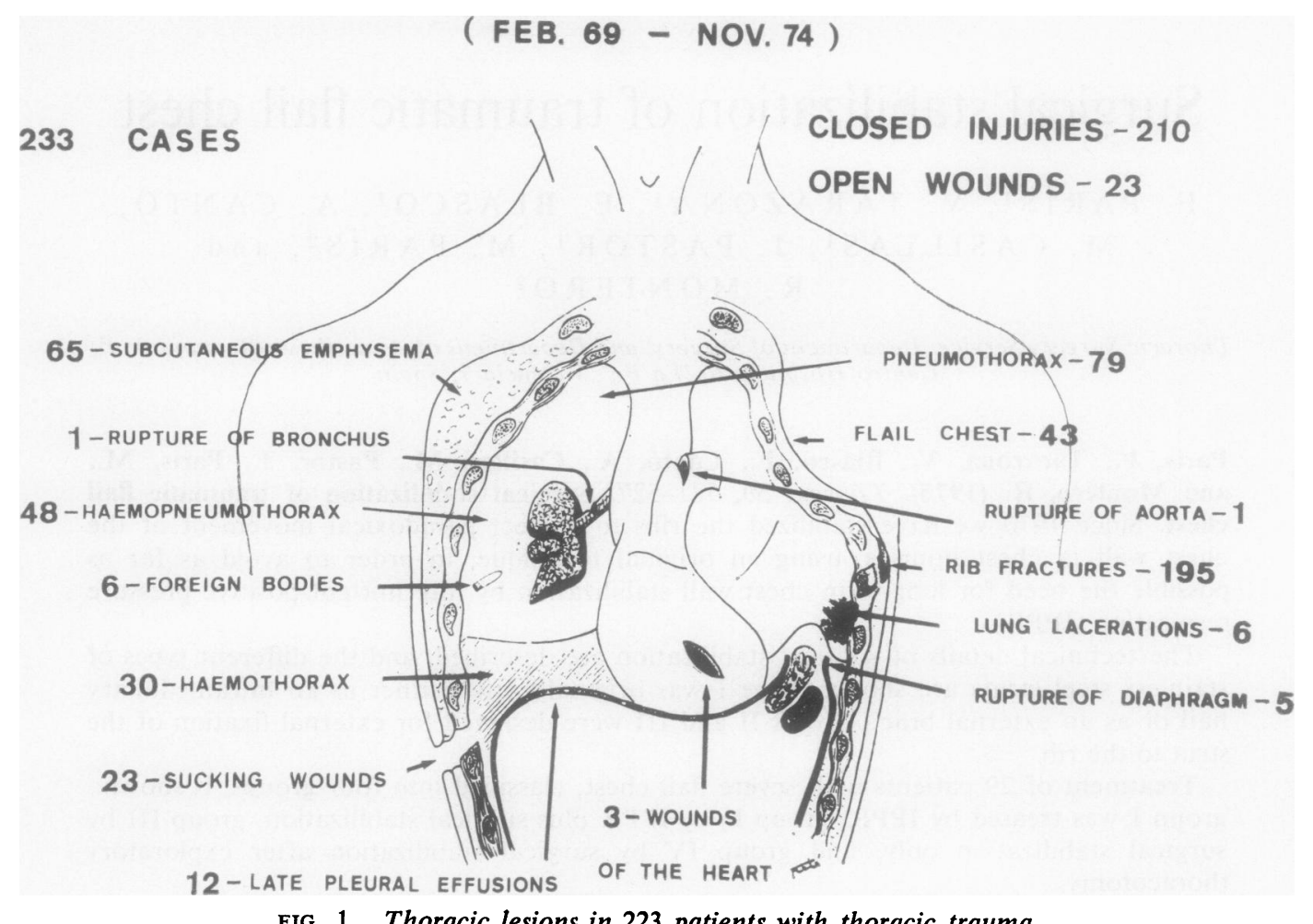

FIG. 1. Thoracic lesions in 223 patients with thoracic trauma.

ulcerative tracheo-oesophageal fístula or damage to the innominate artery.

\section{CLINICAL MATERIAL AND METHOD}

From February 1969 until November 1974 we have admitted 233 patients with chest injuries; 210 were closed injuries and 23 open. Over half were due to road traffic accidents. Figure 1 shows the types of injury and the treatment of the 233 patients is shown in Table $I$.

Patients with severe paradoxical movement of the chest wall have been treated by IPPR as well as by surgical stabilization. Table II shows the treatment of 29 patients with severe flail chest classified into four groups.

T A B L E I

TREATMENT OF 233 PATIENTS WITH CHEST INJURIES

\begin{tabular}{l|r}
\hline \multicolumn{1}{c|}{ Treatment } & No. \\
\hline Symptomatic treatment and observation & 64 \\
IPPR & 27 \\
Closed intercostal drainage & 153 \\
Surgical stabilization of flail chest & 18 \\
Thoracotomy & 19 \\
\hline
\end{tabular}

Some patients had more than one treatment procedure, for example IPPR with closed drainage.
T A B L E I I

TREATMENT OF 29 PATIENTS WITH SEVERE FLAIL CHEST

\begin{tabular}{|c|c|c|}
\hline Group & Treatment & No. \\
\hline $\begin{array}{l}\text { II } \\
\text { III } \\
\text { IV }\end{array}$ & $\begin{array}{l}\text { IPPR } \\
\text { IPPR + surgical stabilization of flail chest } \\
\text { Surgical stabilization only } \\
\text { Thoracotomy + surgical stabilization }\end{array}$ & $\begin{array}{r}11 \\
10 \\
4 \\
4\end{array}$ \\
\hline
\end{tabular}

The types of stainless steel struts designed for us $^{1}$, using the alloy $316 \mathrm{~L}$, are presented in Figure 2. Type I was originally used either as an intramedullary nail or as an external brace. anchored to the ribs by wire sutures (Figure 3). N

The existence in some cases of ribs with $\mathrm{a}_{\mathrm{N}}^{\mathrm{N}}$ medullary canal too small for nailing led us too develop struts of types II and III (Fig. 2) designed for external fixation of the strut to the rib. The addition of a number of holes allows the suture (wire) not only to encircle the strut and rib, but to 0 pass through the strut and rib, avoiding displace-o ment of the prosthesis. The struts are appro- $\triangle$ priately curved and cut with a cold chisel at the time of operation.

${ }^{1}$ Frammer Instruments, Valencia, Spain 
Type I

Non perforated strut. Length $30 \mathrm{~cm}$. Thickness $1 \mathrm{~mm}$. Breadth $5 \mathrm{~mm}$.

Type II

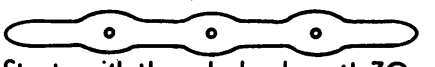

Struts with three holes. Length $30 \mathrm{~cm}$. Thickness $1--2 \mathrm{~mm}:$ Breadth 6--7 $611--12 \mathrm{~mm}$.

Type III

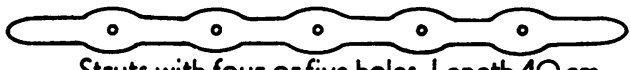

Struts with four or five holes. Length $40 \mathrm{~cm}$.

Thickness $3 \mathrm{~mm}$. Breodth: some os type II.

FIG. 2. Types of stainless steel struts used for rib fixation.

Figure 4 shows different techniques for anchoring type II and type III struts to the ribs. As suture material we have used wire or other nonabsorbable material. Figures 5 and 6 show the chest films of two patients treated by this method.

The struts were placed in position without thoracotomy except in the case of patients in whom thoracotomy was needed because of associated visceral injuries. In cases of lateral flail chest the approach for surgical stabilization was a lateral or posterolateral incision. In cases of anterior or anterolateral flail chest, a vertical midline incision for the approach to the sternum and a lateral incision for the approach to the ribs was used (Figure 7).

\section{RESULTS}

Group I (Table II), with flail chest treated only by IPPR, in our series had a high mortality of $8 / 11(73 \%)$. The cause of this mortality can be explained. All patients in this group had multiple injuries: five had brain injuries and four were in severe shock on admission, and it was for these reasons that surgical stabilization was not carried out.

Group II consisted of 10 patients treated by IPPR plus surgical stabilization of the flail portion of the chest wall. At the time of admission to hospital these patients were unfit for surgical treatment, and the paradoxical movement of the chest wall was treated by IPPR. When the patient's state had improved, surgical stabilization was carried out and the patient was removed from the respirator. All patients in this group had multiple injuries. Three had cerebral injuries, one was in shock on admission, and one was 82 years old. The mortality rate was $4 / 10$. Two patients died in coma from associated brain damage; the paradoxical movement of the chest wall was relieved by the stabilization operation. In another patient the operation was carried out too late and death was due to ulcerative oesophagotracheal fistula and sepsis from too prolonged IPPR. If surgical stabilization had been carried out earlier in this patient, the oesophagotracheal fistula might have been avoided. The fourth patient was operated upon too soon after trauma before cardio-respiratory stability had been achieved. He had an irreversible cardiac arrest at the time of induction of anaesthesia.

Group III consisted of four patients treated by surgical stabilization only, who on admission were in good condition for surgical treatment. None of these patients had multiple injuries, cerebral damage or shock. There was no mortality in this group.

Group IV consisted of four patients treated by surgical stabilization after an exploratory thoracotomy for visceral injuries. One patient died from associated abdominal lesions. The other patient was in severe shock after gunshot injuries to the spleen, colon, diaphragm, lung, and chest wall.

In Table III the extent of rib fractures in 18 patients operated on is shown and its relation to the type of flail chest. In Table IV the site of paradoxical movement and the treatment group are given, showing that in the group of patients

T A B L E I I I

INJURIES IN 18 PATIENTS TREATED BY SURGICAL STABILIZATION

\begin{tabular}{l|ccc}
\hline \multicolumn{1}{c|}{ Fractures } & \multicolumn{3}{c}{ Site of Paradoxical Movement of } \\
& \multicolumn{1}{c}{ Chest } & \\
\cline { 2 - 4 } & Lateral & Anterolateral & $\begin{array}{c}\text { Bilateral } \\
\text { anterior }\end{array}$ \\
\hline $\begin{array}{l}\text { Multiple ribs on one side } \\
\text { Ribs on both sides } \\
\text { Ribs on one side+sternum } \\
\text { Ribs on both sides + sternum }\end{array}$ & -1 & 1 & - \\
\hline Total & - & 2 & 1 \\
\hline
\end{tabular}

T A B LE I V

SITE OF PARADOXICAL MOVEMENT AND TREATMENT GROUP

\begin{tabular}{l|ccc}
\hline $\begin{array}{c}\text { Site of } \\
\text { Paradoxical } \\
\text { Movement }\end{array}$ & $\begin{array}{c}\text { Thoracotomy } \\
\text { Surgical } \\
\text { Stabilization }\end{array}$ & $\begin{array}{c}\text { Surgical } \\
\text { Stabilization } \\
\text { only }\end{array}$ & $\begin{array}{c}\text { IPPR+ } \\
\text { Surgical } \\
\text { Stabilization }\end{array}$ \\
\hline $\begin{array}{l}\text { Bilateral anterior } \\
\text { Anterolateral }\end{array}$ & - & $\overline{1}$ & 4 \\
Lateral & $\overline{4}$ & $\mathbf{3}$ & $\mathbf{5}$ \\
\hline
\end{tabular}



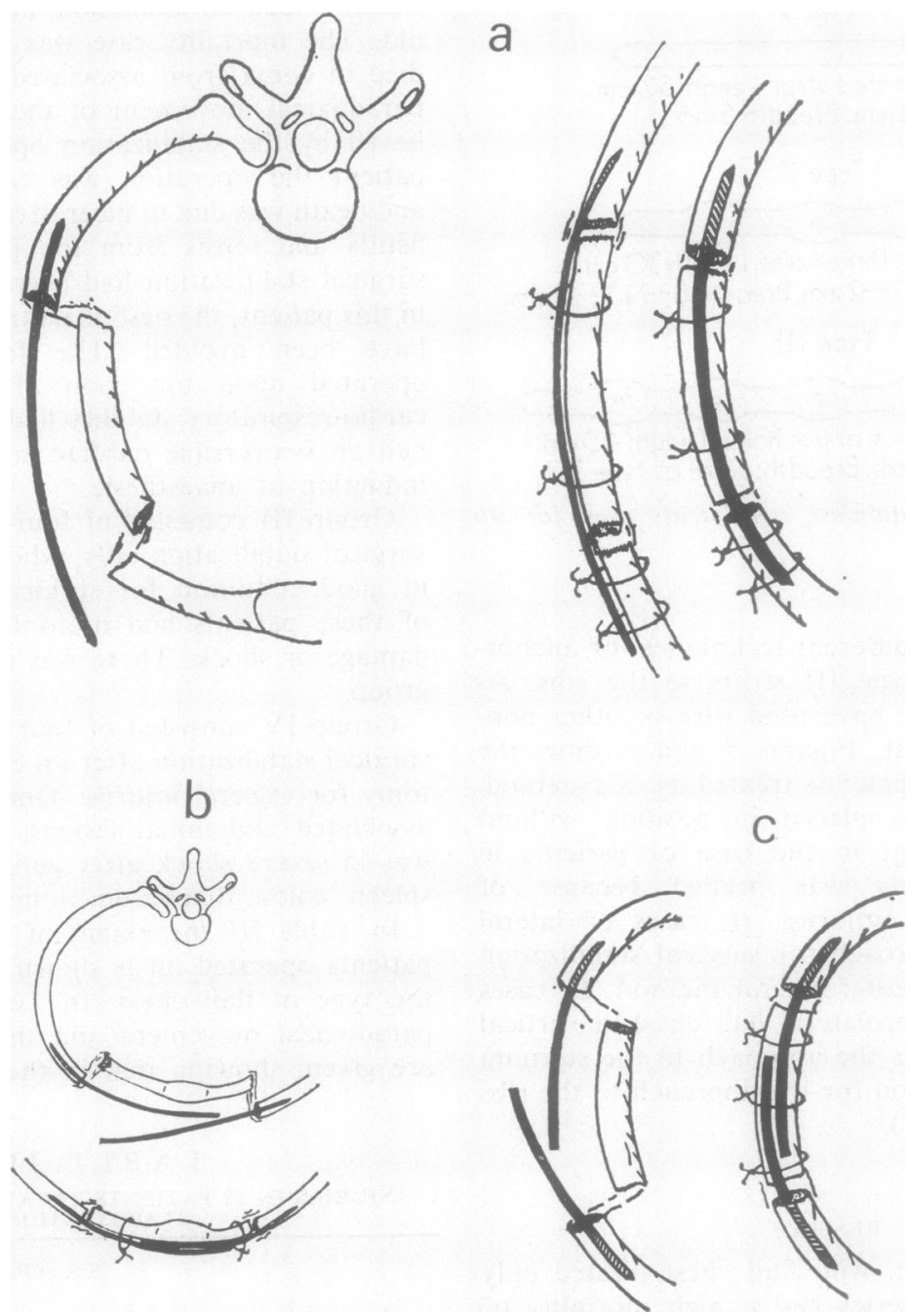

FIG. 3. Fixation with non-perforated struts used as intramedullary nails or external brace: (a) posterior intramedullary nailing and anterior bracing; (b) bilateral intramedullary nailing by two struts crossed and anchored to the anterior floating fragment; $(c)$ similar technique for a lateral fragment in unilateral fractures.

treated by IPPR with secondary surgical stabilization, the paradoxical movement of the chest wall was anterior. In the group 'surgical stabilization only' the lesion was commonly of the lateral type. In Table $\mathrm{V}$ the results of surgical stabilization are given according to the site of paradoxical movement and the type of strut employed. Struts of types I and II were adequate to abolish paradoxical movement of the chest wall in lateral flail chest, but with anterior flail chest the thicker type III strut was required. The results were imper- fect when the thinner types I and II struts were used.

\section{DISCUSSION}

Fixation of fractured rits is, in our view, a method of great value in the treatment of severe fiaid chest. Surgical stabilization of the paradoxica $\vec{D}$ movement of the chest wall can avoid the use of the respirator or at least reduce the interval of IPPR to a short period during initial recovery 

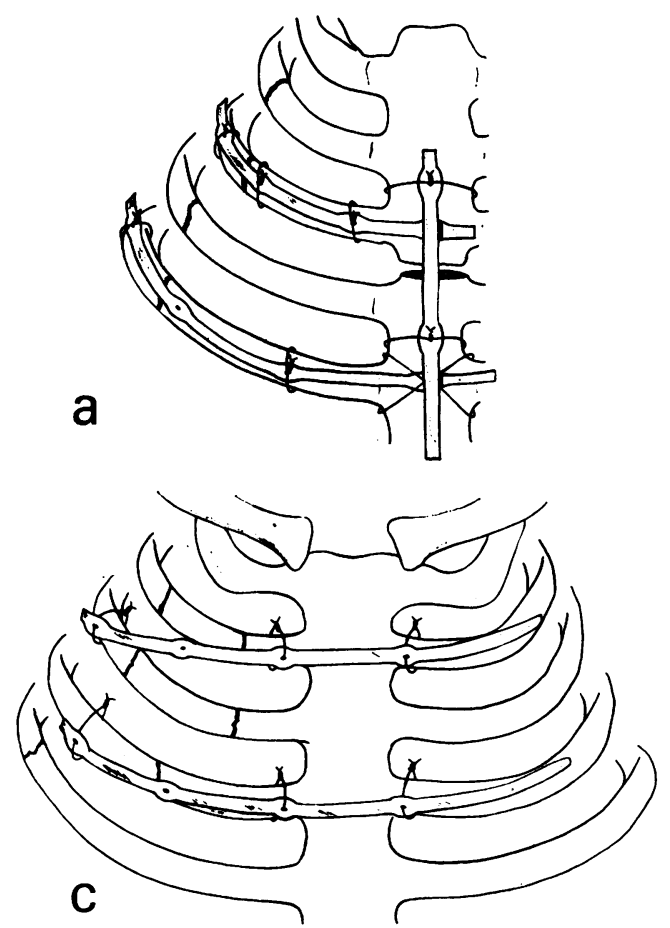
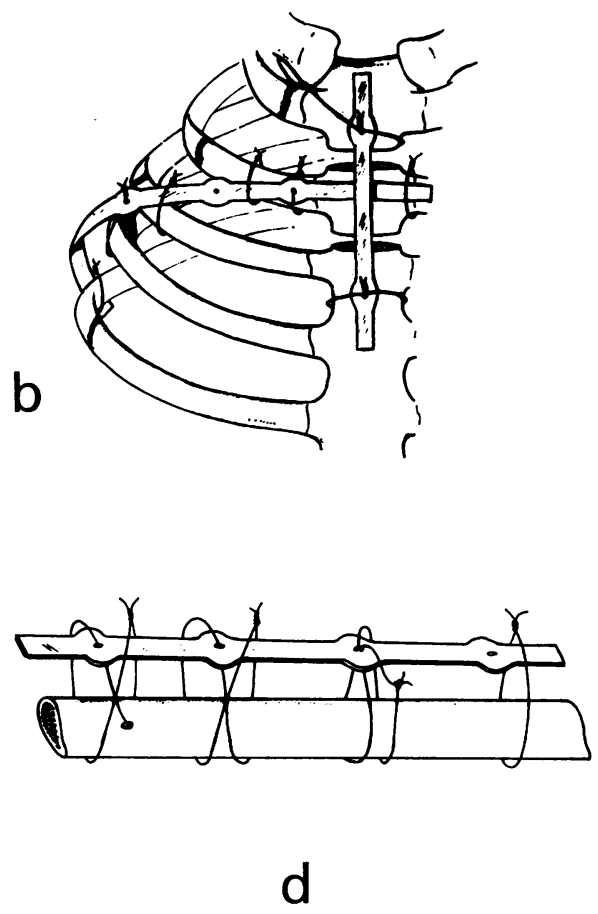

FIG. 4. Fixation with perforated struts: $(a, b$, and c), different methods of anchoring type III struts to the rib cage, in cases of anterior paradoxical movement; (d) types of suture of strut to rib.

from trauma. Its principal aim is to simplify the post-traumatic period by obviating the need for long-term IPPR and avoiding the potential dangers of this procedure. Short periods of IPPR are generally not unsafe.

Surgical stabilization of flail chest must be accompanied by adequate physiotherapy to assist in raising the sputum. The method is not possible if the patient is in coma from associated brain injury or other cause and unable to co-operate.

Using type III struts we have obtained stabilization of flail chest in all cases, even in patients with severe anterior paradoxical movement. The patients' tolerance of surgical stainless steel struts
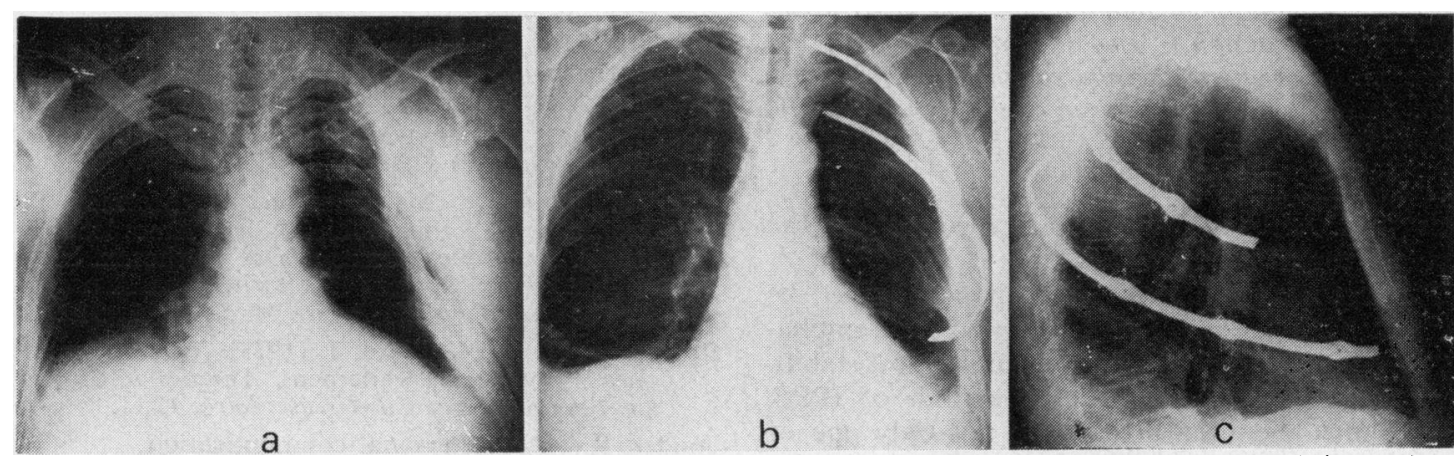

FIG. 5. Radiographs of a patient treated surgically to correct lateral paradoxical movement and depression of the left chest wall: (a) before fixation; $(b, c)$ after fixation. The patient survived and is in good condition two years after injury. 

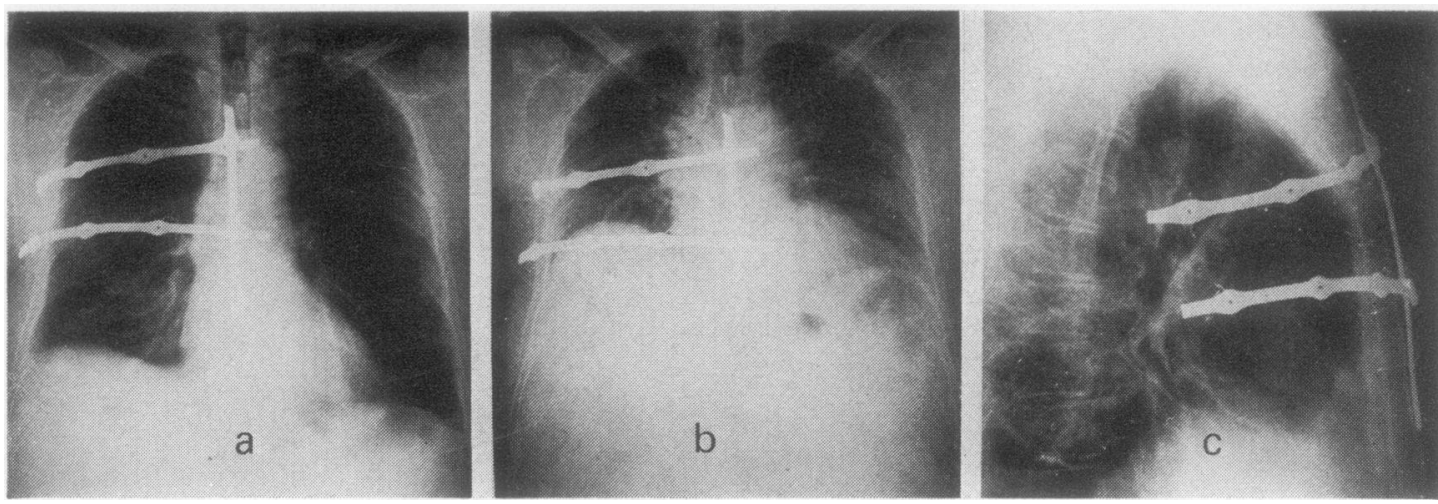

FIG. 6. Postoperative films of a patient treated for severe postraumatic paradoxical movement produced by fractures of right ribs with fracture of the sternum. PA view (a) in forced inspiration, and (b) forced expiration; (c) shows lateral view. The patient survived and is in good condition 18 months after injury.

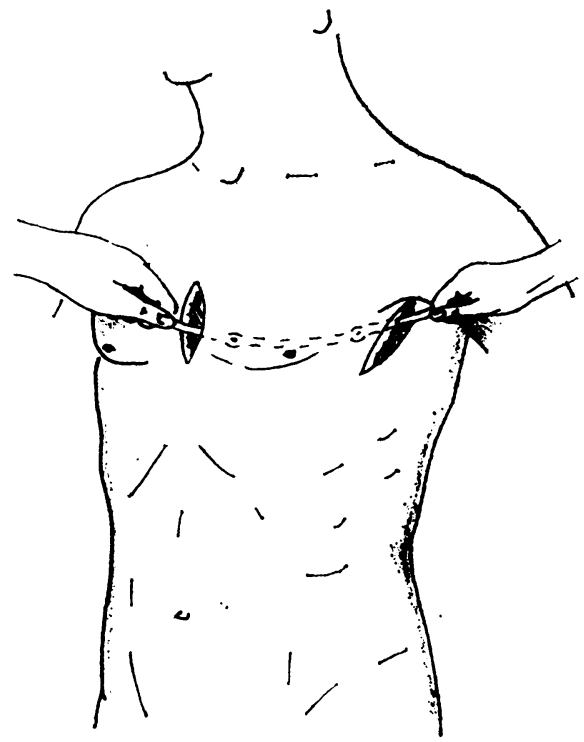

FIG. 7. In anterior or anterolateral flail chest a vertical midline incision is used for the approach to the sternum and a lateral incision for the ribs. The struts pass from one incision to another through a subpectoral plane.

was good. After consolidation of the fractures the struts are removed.

In some circumstances the patient must be treated by long-term IPPR but we must emphasize that the risk of rib and sternal surgical stabilization are increased after long periods of IPPR treatment. Then the problem is not only one of stabilization of the thoracic cage; there is the increased risk of infection of the operation wound from the neighbouring tracheostome and added dangers from established intrapulmonary infection. Early use of surgical fixation, when indicated $\vec{\oplus}$ and possible, may forestall the onset of infection. जै

T A B L E V

RESULTS OF SURGICAL STABILIZATION ACCORDING TO SITE OF PARADOXICAL MOVEMENT AND TYPE OF STRUT USED

\begin{tabular}{l|lll}
\hline \multirow{2}{*}{$\begin{array}{c}\text { Site of Paradoxical } \\
\text { Movement }\end{array}$} & \multicolumn{3}{|c}{ Strut } \\
\cline { 2 - 4 } & Types I and II & Type III & None \\
\hline $\begin{array}{l}\text { Anterior } \\
\text { (bilateral and anterolateral) } \\
\text { Lateral }\end{array}$ & $\begin{array}{l}3 \text { imperfect } \\
\text { 3 good }\end{array}$ & $\begin{array}{l}6 \text { good } \\
4 \text { good }\end{array}$ & 1 good \\
\hline
\end{tabular}

${ }^{1}$ Required additional traction.

\section{REFERENCES}

Avery, E. E., Mörch, E. T., and Benson, D. W. (1956) Critically crushed chests. A new method of treat-ᄋ ment with continuous mechanical hyperventila-3 tion to produce alkalotic apnea and internal 5 pneumatic stabilization. Journal of Thoracic Surgery, 32, 291.

Couraud, L., Bruneteau, A., and Durandeau A. (1973). Volets thoraciques. Indications therapeu-N tiques en fonction de leur siège et du contexte clinique. Annales de Chirurgie Thoracique et 0 Cardiovasculaire, 12, 15.

Dor, V., Noirclerc, M., Chauvin, G., Mermet, B. 0 Kreitman, P., Leonardelli, M., and Amorós, J. F.e (1972). Les traumatismes graves du thorax. Place de l'osteosynthèse dans leur traitement. A propòsō de 100 cas. Nouvelle Presse Médicale, 1, 519.

Eschapase, H. and Gaillard, J. (1973). Volets thoraciques. Principes de traitement. Annales de Chirur-0 gie Thoracique et Cardiovasculaire, 12, 1.

Joudet, R. (1973). Personal communication.

París, F. (1972). Repercusion sobre el mediastino de los traumatismos torácicos. Archivos de Bronco $\times$ neumología, 9, 270. 
_- Cantó, A., Casillas, M., Pastor, J., Blasco, E., and Tarazona, V. (1971). Técnica personal en el tratamiento quirúrgico del tórax fláccido traumático. Libro de Actas de la X Reunión de la Sociedad de Medicina y Cirugia de Levante. Castellón.

Sanchez Lloret, J. (1974). Osteosintesis costal medi- ante placa extraperióstica. Técnica original. Revista Quirúrgica Española, 1, 69.

Requests for reprints to Dr. F. París, Servicio de Cirugia Torácica, Centro Hospitalario 'La Fé', Avenida Alferez Provisional 21, Valencia 9, Spain. 